\title{
Viewpoint Arrangement and Mental Space Configuration: A Cognitive Analysis on Objectivity Construction in Journalistic Narratives
}

\author{
LI Gui-dong \\ Peking University, Beijing, China
}

\begin{abstract}
This paper presents an analysis on how objectivity is discursively constructed in journalistic narratives by drawing on the theories of viewpoint and mental space in Cognitive Linguistics. It is posited that at least three mental spaces are projected by a narrative discourse, i.e., a narrated event space, a narrating space, and a basic space, and the distance between the first two spaces determines the degree of objectivity in the narrative discourse. A schema which represents the configuration of the different spaces is proposed and applied in the analysis of journalistic narratives to explore the strategies of objectivity construction. The analysis reveals that what the different journalistic narratives have in common in the construction of objectivity is to distance the narrated event space and the narrating space with the former being foregrounded in the viewpoint arrangement.
\end{abstract}

Keywords: viewpoint, mental space, objectivity, journalistic narrative

\section{Introduction}

Objectivity is the guiding principle of journalistic reports and is viewed as the critical notion of journalistic professionalism. With respect to objectivity in journalism, in history there was a debate on objectivism and subjectivism in the 1930s and 1940s. Ever since, with the linguistic turn in the study of philosophy and humanities, and the emergence of discourse analysis and narratology, according to Li (2014), there has been a gradual recognition that the objectivity is a symbolic reality and hence is discursively constructed in journalistic narratives.

Simply speaking, narrative is related to storytelling and exists "wherever someone tells us something" (Fludernik, 2009, p. 1). It is found not just in novels or other types of literary writing but is ubiquitous in people's daily life, via which people transmit messages, apprehend and perceive reality. Journalistic reporting can be viewed as a kind of narrating about the events that happen in real life and transmitting them to the public via certain modalities or means of communication. In this sense, it is a kind of storytelling, hence a type of narrative as well. Compared with other types of narrative, narrative may be characterized by its objectivity and truthfulness. However, in many cases, particularly in cases of emergency, journalists are not the first-time witnesses of the

LI Gui-dong, Ph.D. candidate, Institute of Linguistics and Applied Linguistics, School of Foreign Languages, Peking University, Beijing, China. 
reported events. This poses a challenge for the construction of objectivity in journalistic narratives, but also gives rise to the topic for the present study: How is objectivity discursively constructed in journalistic narratives?

This study, following the linguistic turn in humanities, investigates the construction of objectivity in journalistic reports by applying theories of Cognitive Linguistics to narrative analysis so as to deepen our understanding of journalistic professionalism. More specifically, it employs the concepts of viewpoint and mental space in the analysis of journalistic narratives, and exams the roles that different viewing arrangements and mental space configurations play in the achievement of objectivity in journalistic narratives. This paper is structured as follows: It first introduces the theories of viewpoint and mental space in Cognitive Linguistics in the following section. Section three, by combining these concepts and narrative analysis, proposes a cognitive schema for prototypical narrative space configuration. In section four, the schema is applied in the journalistic narrative analysis to explore the strategies of objectivity construction. The final section summarizes the study.

\section{Viewpoint and Mental Space}

\section{Viewpoint and Viewpoint Arrangement}

Viewpoint is a key notion in Cognitive Linguistics. Cognitive Linguistic emphasizes the embodied nature of language. It rejects the modular nature of language as claimed by generative linguistics and claims that human's knowledge of language is associated with general human cognitive abilities. Given this, the same object of conceptualization, depending on the viewpoints of the subject of conceptualization, may have different conceptual representations, referred to as construals, and therefore different linguistic representations. For instance, given the situation in which there is a table and a lamp, their spatial configuration is such that the lamp is over the lamp. Different viewpoints or focus of attention may bring about different construals for the same situation (Langacker, 1987; 2008; Talmy, 2000; Croft \& Cruse, 2004; among others). If the attention of focus is on the lamp, then salience is conferred on it. In this case, the table has the background status. Thus, the situation may be linguistically represented as "The lamp is over the table". Or there may be another way of construing the situation. The conceptualizer might attribute the prominence status to the table, and linguistically code the situation as "The table is below the lamp".

Viewpoint is among the many types of construal operations. According to Langacker $(1987 ; 2015)$, the contrual operation of viewpoint includes two dimensions: vantage point and scope. Vantage point refers to the "location from which a situation is apprehended", and scope, which can be further divided into immediate scope (IS) and maximal scope (MS), refers to "the extent of the content invoked and degrees of centrality imposed by viewing” (Langacker, 2015, p. 123). Figure 1 diagrams the prototypical viewpoint arrangement. 


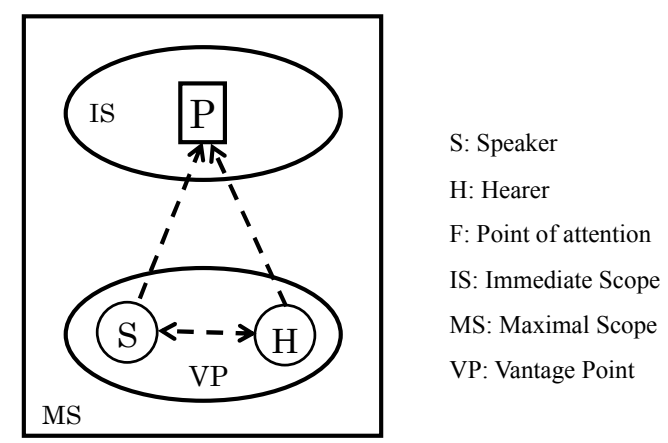

Figure 1. Prototypical viewpoint arrangement.

In Figure 1, the dashed arrows refer to the direction of conceptualization from the offstage conceptualizers, i.e., speaker and hearer, to the onstage point or focus of attention, and the horizontal dashed arrows indicate the interaction between the conceptualizers. As discussed above, a difference in viewpoint arrangements may result in a difference in the construals and linguistic representations. In turn, a difference in linguistic coding may reflect the different construals of conceptualizers for the same situation or the different viewpoint arrangements. Consider:

(1) a. He bought a book yesterday. b. I hear that he bought a book yesterday.

In (1a), the third person subject sentence encodes the objective onstage scene, with the focus being on the referents of he, a book, and their relation, indicated by the small box P in Figure 1. The offstage conceptualizers and the interaction between them are left backgrounded. Therefore, the sentence represents an objective construal. Whereas, (1b) reflects a subjective construal in that it encodes not just the objective onstage scene, but also the offstage conceptualizer's viewpoint or vantage point, as indicated in Figure 1 by the dashed arrow pointing from $\mathrm{S}$ to $\mathrm{P}$.

\section{Mental Space}

The use of language is not just a manifestation of viewpoint arrangement in the contrual operation. It also reflects human's ability of constructing mental spaces (Fauconnier, 1994). According to Langacker (2015, p. 135), mental spaces are the conceptual "working areas" with their particular conceptual contents. Given this conception, the author argues that in the typical viewpoint arrangement, as discussed in the above sub-section, there are projected at least three mental spaces: (1) the space of object of conceptualization, (2) the space of subject of conceptualization, and (3) the basic discourse space. The first space corresponds to the IS, which subsumes elements related to the object of conceptualization. The second space is where the conceptualizers interact. It is also the space of vantage point. The third space pertains to the MS, which includes the first two spaces and subsumes all the conceptual elements related to a usage event, though some of them may not be overtly linguistically represented.

As discussed in the previous sub-section, there is the difference between a subjective construal and an objective construal. The degree of objectivity in construal can be ascribed to the different degrees of distance between the spaces of object of conceptualization and that of the subject of conceptualization. Consider, for instance, the objective construal, in which the object of conceptualization is given the greatest degree of salience, 
while the subject of conceptualization is backgrounded. In this case, the distance between the two spaces is maximal. Likewise, with respect to the subjective construal, the subject of conceptualization is foregrounded to certain extent, and the distance between the two spaces decreases. Therefore, it is argued that different viewpoint arrangements may project mental spaces with different distances.

\section{Schema for Prototypical Narrative Space Configuration}

The previous section introduces the theories of viewpoint and mental space in Cognitive Linguistics. In generally, viewpoint is an operation of construal in which a conceptualizer conceptualizes the object of conceptualization via a particular vantage point. Different arrangements of viewpoint might project different configurations of mental spaces.

Back to the discussion of narrative: As has been introduced, the process of narration can be viewed as one in which the narrator narrates about the events to the narratee via certain means. If we apply the theory of viewpoint in Cognitive Linguistics to narratology, the viewpoints in narratives can be taken as one through which different narrative subjects form conceptualizations over the narrated events. The linguistic representation of this process results in the narrative discourse. Given this, it may be argued that at least three narrative spaces are projected by a narrative discourse: (1) the narrated events space (NES), (2) the narrating space (NS), and (3) the basic narrative space (BNS). A prototypical narrative space configuration is illustrated in Figure 2.

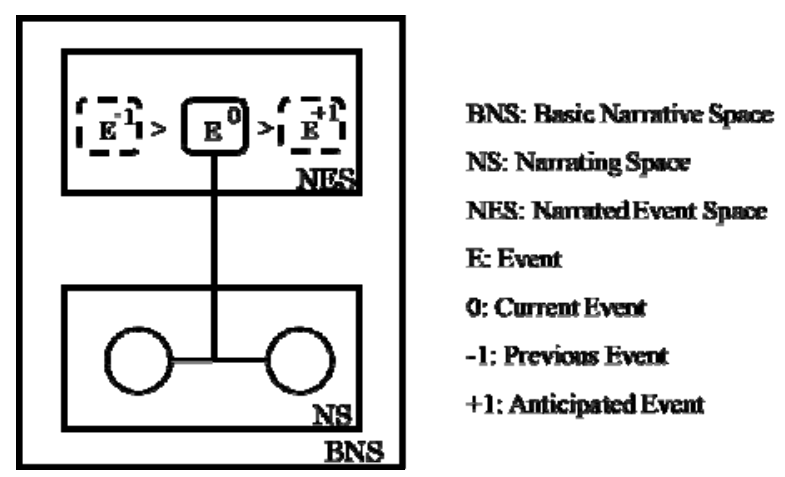

Figure 2. Schema of prototypical narrative space configuration.

Figure 2 shows that a narrative discourse projects a BNS, which subsumes the NS and NES as well as all the other elements that are related to this discourse. NES is the space of the narrated events, and in journalistic narratives, the events are those reported events as happen in reality. More often than not, in a journalistic narrative it may be included more than one event, each of which by itself constitutes a small space within the NES, as indicated in Figure 2 by the small rounded rectangles with numbers indicating their order of occurrence. It must be pointed out, though, at a given time, only one event receives the prominent status, which is referred to as the current event, and indicated by the solid line rectangle with the number 0 . The space constituted by the current event includes such elements as the event participants, their relations, temporal and spatial backgrounds, etc. The NS is the space in which are located the subjects of narration, i.e., the narrator and the narratee, indicated by circles. This is the common ground of the subjects of narration. It includes, in addition to the narrator and narratee, also such elements as the interaction between the narrator and narratee, deictic (time, space, etc.) center, etc. 
As pointed out in the introduction section, journalistic reporting emphasizes on the construction of objectivity and a truthful representation of reality. In a sense, it is a (truthful) reproduction of reality (van Krieken, Sanders, \& Hoeken, 2016, p. 146). Therefore, the challenge for a journalist is to represent, as a non-participant or non-witness, to the receivers what happens in reality. Given this, two aspects are relevant to Figure 2. First, from the perspective of objectivity construction, a journalistic narrative might strive, via linguistic means, to maximize the distance between NES and NS, as the distance between the two spaces is the indication of the degree of objectivity. At the linguistic level, there may be a variety of choices for such a purpose, such as the choice of person pronominal (first person vs. third person), tense (present vs. past), deixis (here, there, now, etc.). Secondly, from the perspective of the receivers' sense of objectivity and truthfulness, a journalistic narrative might also strive to invite the receivers, i.e., narratees, to engage in the conceptualization of the narrated events via the different viewpoint arrangements and the profile of the interaction between the narrator and narratee.

\section{Space Configuration and Objectivity Construction in Journalistic Narratives}

In the previous section, the author proposes a schema for the prototypical narrative space configuration by drawing on the theories of viewpoint and mental space in Cognitive Linguistics. In this present section, the author will apply that schema to the analysis of natural data and explore how objectivity is constructed in journalistic narratives. The data is taken from a journalistic report from Xinhua News Agency, China's official press agency. The report is about a fire that broke out in Harbin, capital city of Northeast China's Heilongjiang Province. ${ }^{1}$

First consider the following excerpt (English translation is mine):

（2）25日凌晨，哈尔滨市消防支队指挥中心接到报警，称松北区太阳岛风景区北龙温泉休闲酒店发生火灾。 指挥中心随即调派太阳岛、道外、利民等消防中队及大吨位水罐车到场处置。5 时03分，太阳岛中队率先到场， 消防部门共计疏散人员 80 余人, 搜救被困人员 20 余人。 7 时 50 分火灾全部扑灭, 经多次搜救排查, 现场发现死亡 人员 18 人, 一名患者在医院救治无效后死亡。

[On the early morning of 25th, the operation center of Harbin Fire Brigade received an alarm call, saying that a fire broke out in the Beilong Hot Spring Leisure Hotel in the Sun Island Scenic Area of Songbei District. The operation center immediately sent the fire brigade in Sun Island, Daowai and Limin, as well as large-tonnage water tankers to control the fire. At 5:03, the Sun Island branch arrived first, and they evacuated more than 80 people and searched and rescued more than 20 people. At 7:50, all the fires were put out. After searching and rescuing for several times, 18 people were found dead, and one other patient died at hospital.]

The narration in this excerpt proceeds in the order of time, as indicated by such time expressions as early in the morning, 5:03, and 7:05. At the linguistic level, it is observed that the narration of every event is expressed with sentences of third person subjects, such as the operation center of Harbin Fire Brigade, the Sun Island Branch, fire, etc. Given the discussion in the previous sections, these pertain to the object of conceptualization. The subjects of conceptualization are not linguistically coded. The schema for the space configuration of this narrative is given in Figure 3.

\footnotetext{
${ }^{1}$ http://www.xinhuanet.com/politics/2018-08/27/c1123333600.htm (accessed on November 13, 2018).
} 

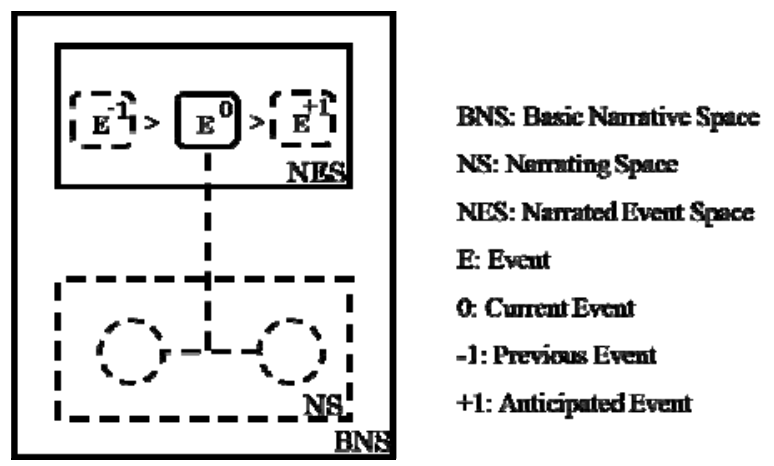

Figure 3. Journalistic narrative space configuration (1).

As shown in Figure 3, with respect to the viewpoint arrangement, the narrated event as the object of conceptualization is put onstage and given a prominent status, while the offstage subjects of conceptualization are hidden and not profiled, as indicated by the dashed circles. In this case, the distance between the NS and NES is maximal, hence the highest degree of objectivity. Actually, this is the strategy frequently employed in journalistic discourses to construct objectivity.

The above analysis reveals that in order to achieve the effect of objectivity, journalistic narratives usually confer prominence on the narrated events, which are typically expressed in sentences with the event participants as the subjects. There are also cases in which the journalists are involved in the narrated events as participants, but they are linguistically represented by such third person nominals as "the journalist", "the reporter", "the writer", etc. For instance:

(3) 记者 25 日上午 10 时许赶到现场时, 夹杂着细雨的空气中仍弥漫着刺鼻的烟味, 消防人员正在冒着烟 的废墟上搜救勘察, 不时有消防车、急救车穿梭。酒店外立面上, 窗户破碎, 墙面被熏成了黑色。进入酒店内部, 脚底下一踩全是灰, 一片大火烧过后的破乱景象。在酒店 3 楼的一间房间内, 门框已被烧得变形, 墙壁黑黢黢的 一碰就掉渣, 屋里的桌子上还放着来不及收拾的电脑和背包。

[When the reporter arrived at the scene at 10 o'clock on the morning of the 25 th, there was still a smell of smoke in the drizzling air. The firefighters were searching on the ruins with smoke. At times, there were fire trucks and ambulances running by. The windows of the hotel were broken, and the outside walls were smoked black. The interior of the hotel showed a chaotic scene after the fire, with the corridors covered with ashes. In a room on the third floor, the door frames were deformed. The walls were black and full of slags. On the desk were left a computer and a backpack.]

This narrative, different from the previous one, involves the participation of the journalist. For instance, at the beginning, the journalist participates in the narration as a "reporter", with the description of his experience and senses, such as arrived at the scene, a smell of smoke in the air, etc. The involvement of the journalist's perspective undoubtly adds to the truthfulness of the narration. However, one question comes up: Will this sacrifice the objectivity in the journalistic narrative? The answer, the author argues, is negative, because as mentioned above, the linguistic use of the third person nominal the reporter in the narrative indicates an objective construal in the viewpoint arrangement, such that there is still distance between the NES and NS. For instance, consider the examples in (4):

(4) a. Don't lie to your mother!

b. Don't lie to me. 
When a mother utters (4a), instead of (4b), to her child, the use of third person your mother, though still identified with the mother as the speaker of utterance, makes the speaker independent of the actual speech event, and represents an objective construal (Langacker, 1987, p. 131; Croft \& Cruse, 2004, p. 62). This seems to be in line with our common intuition. Likewise, back to (3) the use of the third person nominal the reporter indicates an objective construal by distancing the NES and NS in the space configuration. This is shown in Figure 4.

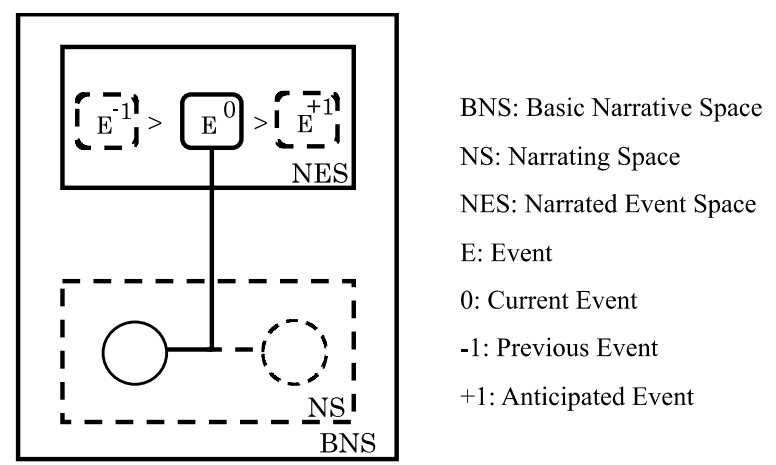

Figure 4. Journalistic narrative space configuration (2).

In it, the involvement of the journalist is indicated by the solid line. However, the use of third person indicates that the journalist is put onstage in the viewpoint arrangement, and hence more of an objective construal.

In addition to the above two cases, there is a third case in which in journalistic narratives are included, either directly or indirectly, the speeches of relevant participants of the narrated events. For example:

(5) “有的人来不及穿衣服就 (从窗户) 跳出来了, 不少住客都还在睡梦中, 我先打了 119 , 又给旅游团负责 人打电话。” 72 岁的住客高仁文说, 不少住客是从外地来旅游, 报警后他们本次旅行团的团长就开始在楼下街边 使劲喊人。

["Some people jumped out (of the window) before they could get dressed, while many others were still in sleep. I dialed first to 119, and then to the head of our tour group", said Gao Renwen, a 72-year-old guest, adding that many guests were actually tourists from other places, and that the head began to shout at the downstairs street after reporting the fire to the police.]

This excerpt cites the speech of a witness of the fire, and therefore involves an event participant's perspective in the discourse, and similar to the previous case it adds to the truthfulness of the news narrative. In addition, there is another dimension of constructing objectivity in it, i.e., highlighting the interaction between the narrator and narratee. More specifically, the use of either direct speech or indirect speech indicates that the narrator invites the narratee to the source of objectivity and truthfulness in the narrative. According to Duijn and Verhagen (upcoming), both direct speech and indirect speech have the intersubjective function in the sense that the speaker invites the addressee to negotiate over a third party's viewpoint. Take for example the sentence containing an indirect speech: He promised that he will arrive on time tomorrow. This sentence also profiles the interlocutors' interaction over the viewpoint of he, in addition to the normal object of conceptualization, i.e., the profile of he will arrive on time tomorrow. In this case, the offstage viewpoint arrangement includes not just the interlocutors, but also he as a conceptualizer. Following Duijn and Verhagen's triadic model of communication, the schema of its space configuration is diagrammed in Figure 5. 


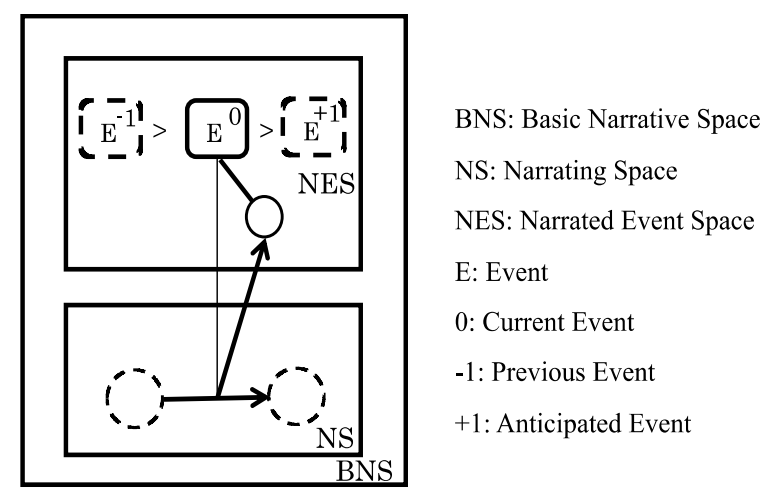

Figure 5. Journalistic narrative space configuration (3).

Figure 5 reveals that the introduction of the event participant's speech profiles both the NES and NS. Such strategy also has the function of the narrator inviting the narratee to the source of objectivity of the narrative, as indicated by the two solid arrows, so as to construct the sense of objectivity and truthfulness in journalistic narratives.

\section{Conclusion}

This study, based on the theories of viewpoint and mental space in Cognitive Linguistics, proposes a schema for the prototypical narrative space configuration, and applies it to the analysis of journalistic narratives in order to explore the linguistic strategies of objectivity construction in journalistic narratives. The analysis shows that the use of different linguistic strategies will manifest different types of viewpoint arrangements so as to adjust the distance between the NES and NS in the space configuration. First, the narration of journalistic discourse might background the vantage point of the offstage narrators and foreground the onstage events, such that the distance between the NES and NS becomes maximal, hence the highest degree of objectivity. Secondly, in order to increase the effect of truthfulness, the journalists' perspectives are often included in the narration. At the linguistic level, the use of third person nominals has the effect of truthfulness while still maintaining a distance between the NES and NS and resulting in a relatively high degree of objectivity. Finally, journalistic discourses often cite the speeches of the participants of the events. Such a strategy, in addition to its function of profiling elements in the NES, also has an intersubjective function, i.e., the narrator invites the naratee to the conceptualization of the source of the narrated events so as to achieve an effect of objectivity and truthfulness.

\section{References}

Croft, W., \& Cruse, D. A. (2004). Cognitive linguistics. Cambridge: Cambridge University Press.

Duijn, M. J. van, \& Verhagen, A. (upcoming). Beyond triadic communication: A three-dimensional conceptual space formodeling intersubjectivity. In D. Glynn and K. Krawczak (Eds.), Subjectivity and stance: Usage-based studies in epistemic structuring. Amsterdam: John Benjamins.

Fauconnier, G. (1994). Mental spaces: Aspects of meaning construction in natural language. Cambridge: Cambridge University Press.

Fludernik, M. (2009). An introduction to narratology. London/New York: Routledge.

Krieken, K. van, Sanders, J., \& Hoeken, H. (2016). Blended viewpoints, mediated witnesses: A cognitive linguistic approach to news narratives. In B. Dancygier, W. Lu, and A. Verhagen (Eds.), Viewpoint and the fabric of meaning: Form and use of viewpoint tools across languages and modalities (pp. 145-168). Berlin: De Gruyter Mouton. 
Langacker, R. W. (1987). Foundations of cognitive grammar: Theoretical prerequisites (Vol. 1). Stanford: Stanford University Press.

Langacker, R. W. (2008). Cognitive grammar: A basic introduction. New York: Oxford University Press.

Langacker, R. W. (2015). Construal. In E. Dąbrowska and D. Divjak (Eds.), Handbook of cognitive linguistics (pp. 120-142). Berlin: De Gruyter Mouton.

Li, Z. (2014). A constructivist interpretation of journalistic reality. Modern Communication (Journal of Communication University of China), 36(11), 55-59.

Talmy, L. (2000). Toward a cognitive semantics (Vol. 2). Cambridge, Massachusetts/London, England: The MIT Press. 